http://dx.doi.org/10.12795/PH.1990.v05.i01.02

\title{
Usos preposicionales en Antigüedades y Principado de la Ilustrísima ciudad de Sevilla, de Rodrigo Caro (1634)
}

Fernando Rodríguez-Izquierdo y Gavala

\section{Introducción}

El estudio de la norma culta actual del habla de Sevilla, que a través de diversos trabajos venimos realizando en equipo en el Departamento de Lengua Española de la Facultad de Filología de la Universidad hispalense, nos impone el deber de reflexionar sobre la historia de dicha norma, de contemplar etapas previas de su diacronía. Las preposiciones, como unidades lingüísticas relacionantes que son, pueden erigirse en índices de un determinado estilo, 0 al menos pueden colaborar a definirlo. Concretamente, la circunstancia de que se encuentra en proyecto o en curso de realización una serie de trabajos sobre usos preposicionales en el habla culta de Sevilla, me ha movido a centrarme en este mismo tema de investigación aplicado a la obra de un sevillano culto del siglo XVII, Rodrigo Caro (Utrera, 1573-Sevilla, 1647): Antigüedades, y Principado de la Ilustríssima Ciudad de Sevilla (1643)1.

Rodrigo Caro es un autor destacado de la llamada escuela poética sevillana del siglo de Oro, grupo caracterizado por una visión desengañada y cansina de la vida, muy acorde por un lado con la filosofía senequista, y por otro con la tendencia al pesimismo y al desaliento propias del barroco. Es sintomática de estos autores la atención que suelen conceder a las ruinas. Francisco de Rioja y Francisco de Medrano compusieron sendos sonetos «A Itálica», y el propio Rodrigo Caro es especialmente conocido por su «Canción a las ruinas de Itálica».

Nuestro autor, aparte de ejercer la carrera sacerdotal y la abogacía, orientó su gran erudición hacia la Arquología, y logró reunir una importante biblioteca y un museo de antigüedades.

${ }^{1}$ Existe una edición facsimilar realizada a partir de la de 1634, por Ediciones Alfar (Sevilla, 1982). Citaremos por número de folio, seguido -en su caso- de v. (=vuelto). 
Además de la obra que ahora nos ocupa, escribió Días geniales o lúdicros, obra de capital importancia sobre el folclore español y el sevillano, Varones insignes en letras de Sevilla, Memorial de Utrera y (también sobre su Utrera natal) Relación de las inscripciones y antigüedades. Además escribió un tratado en lengua latina: Veterum Hispaniae Deorum manes sive reliquiae.

Antigüedades y Principado es una obra que revela vastos conocimientos históricos, lingüísticos y epigráficos. Su tema principal es la historia de Sevilla, y de las instituciones que en ella han tenido lugar a través de los siglos.

\section{Estudio de las preposiciones}

Entrando ya en el tema elegido, debo advertir que en mi estudio de las preposiciones me ha guiado sobre todo el criterio de considerar como tales las que hoy día son así consideradas, sobre todo por dos razones: una, porque de este modo cualquier posible cotejo con los usos comtemporáneos resulta más evidente; la segunda, porque los mismos gramáticos de la época no «se ponen de acuerdo» sobre el paradigma de esta parte de la oración. Nebrija había dado como preposiciones delante, allende, aquende, cerca, lexos, dentro, fuera.... también -curiosamente- hondón (del polo segundo), sin duda en homenaje a Juan de Mena².

Cristóbal de Villalón da una lista de diecisiete preposiciones ${ }^{3}$, en la que no incluye a, bajo, (aunque sí debajo, y ante), ni tampoco desde, en (aunque sí entre), según, sin, so, sobre, tras (aunque sí detrás).

Sin embargo incluye alguna extraña, como apar. Y además hay que añadir que al tratar de la declinación del nombre cita $a$ y para $^{4}$.

Jiménez Patón (1614) da como preposiciones sin, hacia, hasta, pero no cita en, desde, entre, por... En cambio cita la que podríamos llamar preposición compuesta para con ${ }^{5}$.

La primera Gramática de la Real Academia Española (1771) se ajusta más al paradigma que hoy nos es conocido, aunque no aporta bajo, cabe ni so, y, en cambio, curiosamente aporta $\mathrm{como}^{6}$.

${ }^{2}$ Gramática de la lengua castellana, c. XV. Cito por la edición del Profesor Antonio Quilis. Editora Nacional (Madrid, 1981) 195-196.

${ }^{3}$ Gramática Castellana, por el licenciado Villalón. Edición facsimilar y estudio de Constantino García. C.S.I.C. (Madrid, 1971) [48]

${ }^{4}$ Ibid. [17]

${ }^{5}$ Bartolomé Jiménez Patón: Epítome de la Ortografia latina y castellana. Instituciones de la Gramática Española. Estudio y edición de Antonio Quilis y Juan Manuel Rozas. C.S.I.C. (Madrid, 1965). La cita es de Instituciones..., p. 103 (fol. 23 r.)

${ }^{6}$ Cito por la edición facsímil, introducida por Ramón Sarmiento. Editora Nacional (Madrid, 1984) 320321 (pp. 202-203 de la edición original). 


\section{Paradigma de preposiciones halladas. Relativa frecuencia de las mismas}

He investigado los usos preposicionales en Antigüedades y Principado con toda minuciosidad hasta el capítulo XVIII aproximadamente, cuando he visto que empiezan a repetirse los usos. He hecho un recuento numérico que comprende los tres primeros capítulos de la obra.

Según dicho recuento, la preposición más usada, con mucho, es de. Salvo error (como habría que decir con respecto a cada preposición), he contado 281 usos de de en esos tres capítulos. Le sigue en, con 104 usos, y a con 57. Las demás preposiciones tienen relativamente escasos ejemplos de uso: 28 por, 18 con (más 1 consigo), 10 sobre, 7 hasta, 4 para y contra, 2 según y $\sin , 1$ so; no aparecen (aunque sí en otros capítulos) tras y hacia. No he encontrado ningún ejemplo de ante, bajo, cabe.

Aparece sin embargo cerca con valor equivalente al de las preposiciones latinas PROPE, APUD o IUXTA: «y cerca el rio Tinto» (11v), es decir: en uso preposicional sin de. También se encuentra la preposición latina PRO en latinismos: «pro tribunali» $(12 \mathrm{v}), \mathrm{y}$ «escrivir Leptim pro Betim» (30). La preposición de aparece con varios valores latinos:

lat. DE: «Destas cuevas refiere Morgado ay fama» (9)

lat. $\mathrm{EX}$, o DE: «Començando todos de su ethimologia» (1)

lat. OB: («OB Plenissimam Munificentiam», traducido como:) «alaban a Lucio Oracio de plenissima munificencia» (16v)

lat. A, AB: «Esta opinión está favorecida de un autor» (5)

Uso partitivo: «En Sevilla hubo destas thermas» (20).

También, como era de esperar, se encuentra la preposición por usada como equivalente de varias preposiciones latinas:

lat. $\mathrm{A}, \mathrm{AB}$ : «(tesoro) començado a desfrutar por los Phenices» (11v)

lat. PRO: «del verbo Gymno por exercitarse» (23v).

lat. PER: «y esto no es solo opinion, sino legitima probança por los instrumentos, reliquias...» (22v).

Sobre la abundancia de de, es fácil intuir la razón del fenómeno: de es el enlace más frecuente de los complementos nominales, y es por tanto un importante nexo de la llamada «recursividad a la derecha», del tipo «Convento de las recogidas del nombre de Jesús» (27); o bien: «y oy sirve de Consistorio del Juzgado de la Iglesia» (27).

\section{Grafías y contracciones}

Lo que se puede decir de este apartado, sin duda no es todo atribuible a Rodrigo Caro, sino también a los usos gráficos de la imprenta de su tiempo. 
Como grafías curiosas, encontramos la $\mathfrak{f}$ o s alta empleada en preposiciones como sin, sobre, desde...., y también en algún prefijo, como sobreponiendo.

Hasta se encuentra escrito en una ocasión con F- : Fasta, arcaísmo totalmente explicable por darse en cita de la Historia General de Alfonso X (4v). Hazia suele aparecer escrito con $z$, y cõ (con) en la forma abreviada en que aquí se cita: es decir, co y el trazo de nasalización, semejante al superior de la actual letra $\tilde{n}$, sobre la vocal.

En cuanto a contracciones, aparte de las consabidas aun hoy con el artículo, al y del, encontramos también del con el pronombre: «y poniendo (Avieno) a la parte occidental del (se refiere al río Tinto) muchos pueblos»(12).

Igualmente aparecen della, dellos, deste...., aunque no como norma general en forma contracta. También se registra «de esta especie» (13v), e incluso de el: «Se suplen de el mismo epigrama» (22).

Encontramos alomenos, unido en una palabra (7), y a cerca de, escindido en tres palabras (5).

\section{Uso culto de prefijos en relación con preposiciones latinas}

Nebrija, siguiendo a Prisciano, había considerado los prefijos como preposiciones. La definición de Prisciano de preposición como «pars orationis indeclinabilis, quae praeponitur aliis partibus vel appositione vel compositione ${ }^{7}$ parece traducida a la letra por Nebrija: «Preposición es una de las diez partes de la oración la cual se pone delante de las otras, por aiuntamiento o por composición. Como diciendo io vo a casa, a es preposición \& aiunta se con casa; mas diciendo io apruevo tus obras, a compone se con este verbo pruevo e haze con él un cuerpo de palabra» ${ }^{8}$.

Hasta la Gramática académica de 1771 no se establece una distinción clara entre preposición y prefijo?.

Aunque ya el mismo Nebrija observó que algunas preposiciones aparecían solo en composición, como des (desacordar), re (recordar)... ${ }^{10}$. Es decir, con criterio actual, traduciríamos que son prefijos, y no tales preposiciones.

Algunos usos de prefijos en Rodrigo Caro, relacionables con preposiciones latinas o castellanas, pueden ser:

Ante, que -curiosamente- no suele aparecer como preposición, sí aparece como prefijo. Así por ejemplo, tenemos antecogidos por «prendidos»: «Hércules llevando antecogidos los ganados de Gerion por España...» (3v). Igualmente aparecen antepecho (20), antecabildo (22)....

${ }^{7}$ Véase la obra de José J. Gómez Asencio: Gramática y categorías verbales en la tradición española (1771-1847). Edics. de la Univ. de Salamanca (1981) 237.

${ }^{8}$ Gramática de la lengua castellana, 195

${ }^{9}$ Gómez Asencio: o.c., 253

${ }^{10}$ Gramática de la Lengua Castellana, 196. 
Con tiene un curioso uso en cognombre $(14,18 \mathrm{v})$, cognominar $(2 \mathrm{v})$, confutar («refutar») (22), consonar (23)....; sobre en sobrenombre (16v), sobreponer (3v), verbo este último que suele usar Rodrigo Caro con el valor de «añadir»; tras en trasmutaciones (21v), transmigraciones (22).

En cuanto a rastros de preposiciones latinas, se encuentra la forma estonces (2v) (procedente de EX TUNC), citando al Arzobispo Don Rodrigo, forma más cercana a la etimología que la actual «entonces», que por cierto también se documenta (11v, etc....). IN también aparece en intitulado (en Suma de Privilegios), intitular (25), y con valor privativo en el suștantivo infrequencia, voz definida por el autor en términos que hacen pensar en el cultismo estricto (compárese, por ejemplo, con el sintagma «SENATUS FREQUENS») por su valor netamente latino: «por la infrequencia, o falta que avía en Sevilla de ciudadanos romanos» (14v).

Sin embargo, llama la atención el hecho de que, donde se esperaría el término «indudable», Rodrigo Caro elige el popular sin duda: «es cosa sin duda» (23); «este discurso viene a ser legítimo, y sin duda» (23).

$\mathrm{AD}$ aparece en advenimiento; $\mathrm{PRO}$ en prohijamiento (6v), prohijar (17v).... PER en perficionada: «moneda perficionada y batida» (18v), participio analógico donde se evidencia claramente aún el infinitivo latino PERFICERE.

Este uso culto de prefijos es relacionable con otros arcaísmos de la obra, muy propios por demás de un clérigo latinista, como «cudiciosa» (24v), «gladiatores» (24v), «vido» (27)....etc.

\section{Sintagmas preposicionales fomados por acumulación de preposiciones}

Ya Nebrija había observado que «pueden las preposiciones componerse unas con otras, como diziendo acerca, de dentro, adefuera ${ }^{11}$. Este tipo de acumulación no sería $\tan$ frecuente en latín, dada la existencia de casos nominales; si bien en latín vulgar sabemos que se acumularon preposiciones para formar palabras, como DE EX DE> desde, CUM MECUM> comego>conmigo, etc.

Las acumulaciones preposicionales que he recogido en Rodrigo Caro me sugieren a veces usos latinos, como para con, que traduce bastante adecuadamente el ERGA latino: «para con el eran reos» (32).

Otras veces reflejan cierta redundancia superflua, como cuando habla de «un olivar: tras de el qual partio César» (30v); o como cuando se refiere a «hombres de acavallo» (25v). Este último sintagama es obviamente redundante, ya que en otro lugar habla de «la gente de caballo» (29v). También lo vemos emplear por de en uso algo superfluo: «Por de dentro de la ciudad tienen barbacana» (20).

${ }^{11}$ Ibid. 
Resulta interesante encontrar como cultismo, en nota de Martín de Roa previa a al obra, la acumulación latinizante ultra de: «Y ultra de no hallar cosa que contradiga a nuestra santa Fé...»

Otras acumulaciones son más aparente que reales, ya que sirven de vehículo a subordinaciones jerarquizadas y encubiertas por hipérbaton, como «sin por ello incurrir» (en la licencia previa), es decir: «sin incurrir por ello», donde ya hemos hecho desaparecer la acumulación; «para por este camino averiguar» (1)....etc.

Se encuentran además -y esto nos sirve de transición con el apartado siguienteacumulaciones arcaizantes de preposiciones con ciertos adverbios quasi latinos, como yuso y ende. Así encontramos, en cita del Arzobispo Don Rodrigo, «de yuso» y «por ende» (3). Con el sentido de refuerzo de la preposición hasta aparece el adverbio intensificador aun: «aun hasta los muchachos...» (27).

\section{Locuciones adverbiales parcialmente construidas con preposiciones}

En esta misma línea de discurso encontramos allá hazia en cierto ejemplo donde además se registra el uso arcaico del verbo «ser» por «estar»: «Algunos autores dixeron que Tarsis era allá hazia la India Oriental» (10 v).

Es notable en este mismo ejemplo el uso del adverbio direccional allá por el estático allí, tendencia esta muy viva en el siglo de Oro, y hoy vigente en Sudamérica, con algunos restos en nuestra Península: «me encuentro bien acá», «te espero afuera», etc.

Así, en Rodrigo Caro encontramos adentro por dentro: «tiene las letras por la parte de adentro» (3); allá por allí: «nombre también de allá de Syria» (8v). Por constraste encontramos también el uso opuesto: dentro por adentro: «a conducirla dentro della» (26v) (se refiere a «conducir el agua adentro de la ciudad)».

Otras veces se usan estos adverbios con propiedad. Uso estático: «de aquí adelante leeré....» (11). Uso direccional: «no llegan adonde pensaron (15v).

Como ejemplo de redundancia que podamos citar, encontramos en donde, uso que llega hasta hoy: «En donde oy vemos la Parrochia de San Nicolas» (9).

Usos curiosos de economía de preposición a: demas por además: «demas del antepecho que ocupan las almenas» (20), «demas de la mucha fee de su autor» (22). Conforme por conforme a: «cada una (ciudad) conforme su possible» (24v).

Giros adverbiales (y preposicionales) de gran expresividad: «muy de propósito» (5), «sin nota de temeridad» (5), «sin descuento de tantas enfermedades y guerras como después huvo» (5v), «por ventura» (9), «junto con aver» (11v) (por «además de haber»), «juntamente con» (21) (por «al mismo tiempo que»), «en circuito» (20) (por «alrededor») «en el interin» (30) (por «mientras»).

Aun cuando usa estas expresiones, más o menos cultas, Rodrigo Caro no desdeña tampoco la expresión castiza, cuando dice -por ejemplo-hablando de Lepe: «porque cae muy a trasmano» (29v). 


\section{Uso de preposición $A$ ante complemento directo}

Ya Nebrija había dado carta de validez a dos expresiones como «io amo al proximo» y «amo el proximo» ${ }^{12}$. La vacilación en el uso de $a$ ante complemento directo personal es frecuente. El autor anónimo de la Gramática de Lovaina (1559) postula a para marcar el Dativo o tercer caso, y ausencia de $a$ para el Acusativo o cuarto caso ${ }^{13}$. Un año antes (1558), Cristóbal de Villalón había dado como ejemplo paradigmático de Dativo «para Pedro», y de Acusativo «a Pedro»14. Jiménez Patón (1614) distinguía cuidadosamentte el uso de verbos transitivos con «cosas animadas», que rigen $a$, del uso de los mismos con «cosas sin alma» que no llevan $a$, como: «amo la verdad, leo los libros, oyo el evangelio» ${ }^{15}$.

El uso de Rodrigo Caro de este rasgo gramatical es aparentemente algo anárquico, aunque se pueden observar en él ciertas constantes. Podemos pues afirmar que:

a) No usa sistemáticamente $a$, ante complemento directo personal; más aún, frecuentemente deja de emplear dicha preposición:

-ante sustantivos abstractos personales: «(Griegos y Romanos) tuvieron notable cuidado en criar bien la juventud» (23v)

-ante sustantivos concretos personales: «para castigar los malos» (7) «los capitanes que guiaron esta gente» (11v)

-a veces aun a costa de cierta ambigüedad: «alentarian los pueblos los Magistrados romanos» $(24 \mathrm{v})$

-incluso en los casos de «doble acusativo latino», como con el verbo «enseñar»: «enseñando (Hercules Egypcio) la gente de aquel rudo siglo mas policia, que (= de la que) hasta allí habían tenido» (6)

b) Pero:

-usa $a$ ante complemento directo de cosa: «miró $a$ este pensamiento» (7v)

-usa $a$ redundantemente ante complemento directo de persona en contextos donde hoy fácilmente se omite: «Véase a Morgado en el libro 4 de la historia de Sevilla» (22v) -sobre todo: usa casi sistemáticamente $a$ cuando el complemento directo es «Sevilla», tal vez en un inconsciente intento de personalización, o al menos de homenaje:

«El tomar Julio César $a$ Sevilla, fue a los nueve de Agosto deste año de 43» (31) «avia fundado Hercules $a$ Sevilla» (4) «los Romanos señorearon $a$ Sevilla» (21), etc.

${ }^{12}$ Ibid., 177

${ }^{13}$ Anónimo: Gramática de la lengua vulgar de España. Lovaina, 1559. Edic. facsimilar y estudio de Rafael de Balbín y A. Roldán. C.S.I.C. (Madrid, 1966) 32.

14 Villalón: o.c., 16.

15 Jz. Patón: o.c., p. C. 
-la preposición $a$ se encuentra a veces en contextos ineludibles, como: «que no pueden embarcarse unos $a$ otros» (25v), o bien para deshacer ciertas ambigüedades:

«los de César cogieron un soldado, que avia muerto $a$ un hermano suyo en el real» $(30 v)$

\section{Usos de preposiciones en regímenes verbales (suplemento)}

Hs

Me limitaré a mencionar ciertos usos de la construcción que el Profesor Alarcos Llorach ha denominado «suplemento» ${ }^{16}$.

Encontramos «juzgar por» con el sentido de «considerar»: «pues tener fama, y ser juzgados por los mas doctos...» (7). También «deponer de» como «informar sobre»: «El Turonense depone desta costumbre» (21v). Encontramos «divertirse a» en un modo de difícil paráfrasis, como «dividirse en», o «apartarse a»: «Diviertese esta fuente a la parte setentrional de Sevilla $a$ muchas fuentes públicas» (26v).

También emplea «usar de» (continuando en cierto modo el uso latino de UTOR con ablativo), «vestirse de»: «se vestían de lana, y (...) aun no usavan de lienço» (27). También «triunfar de» (22) «ocuparse en» (12v).

Es curioso, por contraste, comprobar que una construcción que hoy usamos suplementada, como es la del verbo «desesperar», la usa Rodrigo Caro sin preposición:

«desesperando los Romanos la vitoria, se valieron de la traicion» (27v).

\section{Ausencia de artículo tras preposición}

Es bien conocida la virtualidad determinante de la preposición, que en ciertos sintagmas suple la función que podía desempeñar un artículo tras ella. Esto ocurre principalmente cuando sigue a la preposición una oración adjetiva de relativo, que también es determinante de algún antecedente previo. Los ejemplos pueden ser clásicos o actuales. Citaré uno de Rodrigo Caro: «en la montaña sobre que aquella villa está fundada» (26).

Además, se da la misma construcción ante un que conjuntivo (también interpretable como pronombre relativo si, catalizando «el hecho» lo interpretamos como «el hecho de que...»): «Esto se corrobora, con que de la misma Santa Iglesia mayor se sacó el mármol» (22).

Por lo demás, resulta sorprendente alguna ausencia de artículo entre preposición e hidrónimo o nombre propio de río: «en la ribera de Guadalquivir»; si bien, dos líneas más abajo dice: «en la ribera del Betis» (26v). 120.

${ }^{16}$ E. Alarcos Llorach: Estudios de gramática funcional del español. Gredos. $2^{\mathrm{a}}$ ed. (Madrid, 1.978) 117- 


\section{Usos sorpresivos de preposiciones aparentemente cambiadas por otras}

Los Profesores Alonso Zamora Vicente y María Josefa Canellada, en su edición del Manual de escribientes de Antonio de Torquemada (h. 1552) ${ }^{17}$, aportan una relación de preposiciones empleadas en la época con uso distinto del actual. El mismo propósito me guía en estos momentos, con relación a Rodrigo Caro.

Citaré algún ejemplo, tratando de ser breve. La preposición en se encuentra empleada, bien con valor de $a$ («de passar en Africa» (29) -recordemos que IN con acusativo tenía este valor dinámico en latín-), bien con valor de de («en esta manera» $(12 v, 19 v)$, «en ninguna manera» (19v)), bien con valor de entre («y en ellos uno» (15)).

También encontramos ausencia de en donde era de esperar la preposición: «(los Magistrados, que en Sevilla) se aposentavan el Invierno» (23). Por contraste, aparece en redundantemente donde no es necesario, como: «en la segunda vez que acá vino (César)» (28).

Análogas observaciones pueden hacerse respecto a otras preposiciones, cuya relación omitimos por no alargar. También advertiremos que, pese a que media escasamente un siglo entre el citado libro de Torquemada y Antigüedades, y Principado de Rodrigo Caro, se observan bastantes afinidades en el uso de las preposiciones.

\section{Consideraciones sobre el estilo, y conclusión}

Las preposiciones son nexos, enlaces de subordinación. Dado que el ser humano no se expresa normalmente por sustantivos esenciales, que definan lapidariamente esencias, sino por medio de giros, cláusulas, perífrasis, sintagmas en suma..., que intentan acercarse al misterio de la realidad, describiéndola más o menos propiamente, las preposiciones resultan ser elementos privilegiados para mostrar por medio del estilo relaciones entre palabras. El uso o la deliberada supresión de preposiciones puede jugar un importante papel estilístico.

Los ejemplos que hemos visto de Rodrigo Caro, a los que se podían añadir muchos más, no son sino instancias de libre elección, en su mayoría, donde nuestro autor ha dejado huellas de su personalidad. Advertimos en su obra, tanto expresiones cultas, prácticamente continuadoras de usos latinos, como giros populares, que sin duda Rodrigo Caro captaría por las calles de Sevilla. Las posibles alternativas no empleadas, presentes sólo en el paradigma, dan fe de este ejercicio de estilo.

El visible arcaísmo de ciertas construcciones nos habla de una innegable fidelidad a la época, a ese siglo de Oro en que se consolidó la lengua de cultura, y la lengua literaria que hoy conocemos.

Dos sencillos ejemplos para terminar, uno de uso y otro de abstención. Resulta trivial la expresividad del sintagma "poner en duda». En el texto de Rodrigo Caro

${ }^{17}$ Obra publicada en Anejos del Boletín de la R.A.E. (Madrid, 1.970) 32-33. 
hallamos la siguiente construcción, que nos devuelve cierto sentido de frescura de la construcción original:

«han ossado poner duda en la verdad de aquel Chronico» (22).

Consideremos ahora el ejemplo de abstención. Frente a la obvia construcción «brotar de» («el agua brota de la fuente»), Rodrigo Caro elige con innegable estilo, transitivizando el verbo:

«el agua, que espontáneamente las fuentes brotavan» (26).

También la prosa culta de Rodrigo Caro, como hemos visto, brota espontáneamente un uso esmerado de las preposiciones, digno de nuestra más fervorosa atención. 